\title{
TEACHERS' AWARENESS OF STUDENTS WITH AUTISM SPECTRUM DISORDERS
}

\author{
Svetlana V. Lezhenina ${ }^{1 *}$, Nadezhda V. Shuvalova ${ }^{2}$, Tatiana M. Kozhanova ${ }^{3}$, Oleg N. \\ Viktorov $^{4}$, Sergej V. Smelov ${ }^{5}$, Antonina V. Karpunina ${ }^{6}$, Zhanna S. Vasilieva ${ }^{7}$ \\ ${ }^{1}$ Assoc. Prof., Chuvash State University, RUSSIA, svl-8@bk.ru \\ ${ }^{2}$ Prof., Chuvash State Pedagogical University, RUSSIA, msta77@yandex.ru \\ ${ }^{3}$ Assoc. Prof., Chuvash State Pedagogical University, RUSSIA, kuez-nir2@bkl.ru \\ ${ }^{4}$ Assoc. Prof., Chuvash State University, RUSSIA, viktorovon@mail.ru \\ ${ }^{5}$ Prof., Chuvash State University, RUSSIA, dimapotapov20@gmail.com \\ ${ }^{6}$ Assoc. Prof, Chuvash State University, RUSSIA, svl-888@bk.ru \\ ${ }^{7}$ Assoc. Prof., Chuvash State University, RUSSIA, zhannav2204@gmail.com \\ ${ }^{*}$ Corresponding Author
}

\begin{abstract}
This article considers the problems of inclusive education from the point of view of teachers' awareness of autism spectrum disorders in children. At present, all over the world, much attention is paid to inclusive education. Therefore, in 2003, the National Council for Special Education (NCSE) was created in Ireland, providing a 12-stage education system for children with disabilities. Finland also pays great attention to the education of persons with ASD (Autism Spectrum Disorders).

The aim of the study is to determine the level of teachers' awareness of students with autism spectrum disorders. An interview questionnaire was developed, which included five questions. The study involved 188 teachers of educational organizations of various levels: 52 respondents $(27.6 \%)$ were teachers of preschool education (first level); 136 respondents $(72.4 \%)$ were teachers of primary education (second level). 182 $(96.8 \%)$ of the respondents worked in general educational organizations and $6(3.2 \%)$ - in specialized institutions for children with ASD (first and second levels). The study showed that more than half of teachers $(51.6 \%)$ rated their knowledge of autism spectrum disorders in children as satisfactory. A quarter $(22.4 \%)$ of the respondents rated their knowledge as unsatisfactory. One-fifth (17\%) rated their knowledge as good and one tenth of the respondents (9\%) assessed their knowledge as excellent. It remains optimistic that more than $90 \%$ of the respondents, regardless of the awareness level of ASD in children, would like to learn more about this problem and need additional information.

This finding is extremely important for raising awareness of ASD. This aims to create different levels of educational programs to help teachers. It is alarming that most of the teachers do not want to work with children with ASD. The authors of the article believe that it is the lack of information that leads to the reluctance of teachers to work with children with ASD and, possibly, is the cause of various psychological problems among teachers.
\end{abstract}

Keywords: Autism spectrum disorders, children, educators, awareness level, inclusive education. 


\section{INTRODUCTION}

At present, all over the world, much attention is paid to inclusive education. Therefore, in 2003, the National Council for Special Education (NCSE) was created in Ireland, providing a 12-stage education system for children with disabilities. (Bogacheva, Ivanov, 2019, pp. 21-29; Vysotina, 2013). Finland also pays great attention to the education of persons with ASD (Autism Spectrum Disorders ASD) (Golubkova, 2018; Gurovich, 2007, pp. 5-9).

Autism is a disease characterized by a pronounced and comprehensive deficit in social interaction, communication, as well as limited interests and repetitive stereotypical actions (Isaev, 2007, 150 p; Kovalev, 1988, pp. 3-7).

According to "Autism Speaks" organization (2017), there are over 70 million people with autism worldwide.

In 2013, the term "Autism Spectrum Disorders" (ASD) was appeared.

The modern concept of ASD covers different groups of neurodevelopmental disorders, including early childhood autism, or Kanner's syndrome, Asperger's syndrome, high functioning autism, atypical autism, childhood disintegrative disorder, as well as many chromosomal and genetic syndromes.

The number of people with ASD is growing rapidly (Koren, Kupriyanova, 2013, pp. 61-68; Krasilnikova, 2012, pp. 114-123; Lvova, Khalfin, Syrtsova and Allenov, 2018, pp. 10-18). According to forecasts, in 2025 every second inhabitant of the planet will suffer from this disorder to one degree or another (Nikolskaya, Baenskaya and Libling 2014, 288 p.; Salnikova, Movina, 2002, pp. 109-111). A significant obstacle to studying the ASD epidemiology arises from the differences in the accounting classifiers.

In the Russian Federation, there are the following models of teaching children with ASD: an inclusive group, an inclusive class, a resource class, an autonomous class, and individual education of a student with ASD at home.

Despite the successes achieved in this area, there are many problems associated with the inadequacy of the regulatory framework development, as well as the organizational and methodological support of the process of teaching children with ASD in the context of inclusive education. Lack of teachers' awareness about the treatment options for children with ASD, its causes, and preventive measures can cause teachers to have psychological difficulties such as anxiety, stress, and unwillingness to work with children with ASD.

The aim of the study is to determine the level of teachers' awareness about students with autism spectrum disorders.

\section{MATERIALS AND RESEARCH METHODS}

The study involved 188 teachers of educational organizations of various levels: 52 respondents $(27.6 \%)$ were teachers of preschool education (first level); 136 respondents $(72.4 \%)$ - teachers of primary education (second level). $182(96.8 \%)$ of the respondents worked in general educational organizations and $6(3.2 \%)-$ in specialized institutions for children with ASD (first and second levels).

The age of the subjects ranged from 23 to 59 years (average age $-35.5+/-6.5$ years).

When analyzing the length of service, it was revealed that the work experience of the respondents from 0 to 5 years was noted by $80(42.5 \%)$ people, from 5 to 10 years -14 (7.4\%), from 10 to 20 years $-34(18,2 \%)$, from 20 to $30-35$ (18.6\%), 30 and more $-25(13.3 \%)$.

The study was conducted in the city of Cheboksary, the Chuvash Republic, the Russian Federation, between 2018 and 2020.

To achieve this goal, we used a specially developed questionnaire-interview to assess the level of teachers' awareness about autism spectrum disorders in children. The questionnaire includes 5 questions. It was created based on a questionnaire (Ivanov M.V., Bogacheva O.I.).

Questions of the interview-questionnaire for teachers to determine the level of awareness about ASD:

1. How do you generally assess your knowledge of ASD in children?

2. Would you like to learn more about ASD in children?

3. Where did you get your knowledge about ASD in children?

4. In your opinion, what features of mental activity relate to children with ASD? 


\section{Do you want to work with children with ASD?}

The results were assessed separately for each item of the questionnaire, as well as by calculating the arithmetic mean.

\section{RESEARCH RESULTS}

When asked how you generally assess your knowledge of autism spectrum disorders in children, 97 (51.6\%) teachers rated it as satisfactory; $42(22.4 \%)$ respondents rated their knowledge as unsatisfactory; $32(17 \%)-$ as good; $17(9 \%)$ respondents rated their knowledge as excellent.

When asked if you wanted to know more information about ASD in children, 175 (93.1\%) of the interviewed teachers answered that they would like to learn more information about ASD in children and need additional information on this issue. $13(6.9 \%)$ respondents answered that they do not need additional information. It is possible that these teachers are just working with children with ASD.

When asked where you got your knowledge about autism spectrum disorders in children, $118(62.8 \%)$ of the respondents answered that they studied at the university. At the same time, $7(3.7 \%)$ of the interviewed teachers answered that they studied at the advanced training courses, $22(11.7 \%)$ indicated that they studied independently. 41 (21.8\%) respondents do not know about autism spectrum disorders and have not studied it anywhere.

To the question "In your opinion, what features of mental activity relate to children with ASD?", the majority, $60(31.9 \%)$ teachers, answered that they included violations of social interaction. $54(28.7 \%)$ people attributed various persistent limited, repetitive and stereotyped forms of behavior, interests and activities, as well as other problems of behavior to the characteristics of children with ASD. 34 (18.1\%) respondents referred to children with ASD as severe disorders and distortions of the need for communication, Deficiency of verbal and non-verbal forms of communication, including all types of speech (oral, written speech) were indicated as features of children with ASD $36(19.2 \%)$ of respondents, $4(2.1 \%)$ respondents noted complex mental development disorders, which are characterized by social maladjustment and inability to social interaction, communication and stereotyped behavior.

When asked if you want to work with children with ASD? 165 (87.7\%) teachers gave a negative answer. 6 (3.2\%) people answered that they work with children with ASD and $17(9.1 \%)$ respondents found it difficult to answer.

The results were assessed separately for each item of the questionnaire, as well as by calculating the arithmetic mean.

\section{CONCLUSIONS}

The study showed that more than half of teachers $(51.6 \%)$ rated their knowledge of autism spectrum disorders in children as satisfactory. A quarter $(22.4 \%)$ of the respondents rated their knowledge as unsatisfactory. One-fifth (17\%) - as good and one-tenth of the respondents (9\%) assessed their knowledge as excellent. It remains optimistic that more than $90 \%$ of the respondents, regardless of the awareness level of ASD in children, would like to learn more about this problem and need additional information. This finding is extremely important for raising awareness of ASD. This aims to create different levels of educational programs to help teachers. It is alarming that most of the teachers do not want to work with children with ASD. The authors of the article believe that it is the lack of information that leads to the reluctance of teachers to work with children with ASD and, possibly, is the cause of various psychological problems among teachers.

\section{REFERENCE LIST}

Bogacheva, O.I., Ivanov, M.V. (2019). Features of maternal attitudes towards the disease of children with autism spectrum disorders. Issues of mental health of children and adolescents, 3 (19).

Golubkova, M. (2018). The doctor is turning: The concept of 4P-medicine will require restructuring of the vocational education system. Rossiyskaya Gazeta.

Gurovich, I. Ya. (2007). Saving (preventive) psychosocial rehabilitation. Social and Clinical Psychiatry, vol. $17,1$. 
Isaev, D.N. (2007). The attitude of parents and the child's illness. Psychology of the family and the sick child.

Koren, E.V., Kupriyanova, T.A. (2013). Family burden as a target of psychosocial rehabilitation of children and adolescents with mental disorders. Journal of Neurology and Psychiatry named after S.S. Korsakov, vol.113, 5.

Kovalev, V.V. (1988). Issues of deontology of childhood and adolescence. Journal of Neurology and Psychiatry named after S.S. Korsakov, vol. 88, 8.

Krasilnikova, E. D. (2012). Psychological characteristics of families raising children with various types of mental development disorders. Questions of mental health of children and adolescents, 2 (12).

Lvova, D.P., Khalfin, R.A., Syrtsova L.E. and Allenov, A.M. (2018). Development of forms of interaction between medical specialists and patients. Russian Psychiatric Journal, 5.

Nikolskaya, O.S., Baenskaya, E.R. and Libling M.M. (2014). Autistic child. Ways to help.

Salnikova, L.I., Movina, L.G. (2002). Map for assessing the level of knowledge about mental illness and the effectiveness of the psychoeducational program. Manual on psychosocial treatment and psychosocial rehabilitation of mentally ill patients.

Vysotina, T.N. (2013). Features of parental attitudes towards children with atypical autism. 